\title{
Managing the infraorbital sulcus of ageing
}

André Camirand MD, Jocelyne Doucet RN, June Harris MD

Chirurgie Esthétique et Plastique, Montréal, Québec, and Faculty of Medicine, Memorial Univeristy of Newfoundland, St. John's Newfoundland

A Camirand, $\mathbf{J}$ Doucet, $\mathbf{J}$ Harris. Managing the infraorbital sulcus of ageing. Can $J$ Plast Surg 1996;4(4):221-223. The pathophysiology of the infraorbital sulcus is presented. A suggested technique to manage this consequence of ageing is to reposition the premalar fat pad properly by manipulating the superficial musculo-aponeurotic system. The result is a natural, youthful appearance.

Key Words: Enophthalmia, Herniated fat pads, Infraorbital sulcus, Palpebrojugal sulcus, Palpebromalar furrow, Premalar fat pads

\section{Correction du sillon palpémomalaire}

RÉSUMÉ : Nous décrivons la pathophysiologie du sillon palpébromalaire. Nous présentons les différentes façons d'améliorer cette conséquence du vieillissement du visage et de l'oeil. Notre technique préférée consiste à relocaliser la graisse prémalaire à l'aide du SMAS, ce qui nous accorde un résultat naturel de rajeunissement.

Charpy and Nicholas (1) were probably the first to describe the premalar fat pad; they called it the "graisse prémalaire". This fat pad descends as people age, like most structures of the face (eg, the eyebrow, the lateral canthus). As a consequence, the malar bone and the inferior orbital rim become subcutaneous and an infraorbital sulcus, also called the palpebrojugal sulcus of Charpy or the palpebromalar furrow, forms. Concomitantly, herniated fat pads occur in the lower eyelids which make the sulci even more obvious because of the superimposed convexity. The herniated fat pads also cause an enophthalmia of ageing, and the infraorbital sulcus aggravates the sunken look of the ageing eye. These are some of the most obvious signs of ageing in the face and eye. To restore a youthful appearance, these signs must be understood and managed.

\section{MANAGEMENT}

Loeb (2) may have been the first surgeon to try to manage the nasojugal depression by sliding herniated fat pads in or grafting this fat to level the defect. Hamra (3) also mobilized the herniated fat pad from the lower eyelid to fill in the infraorbital sulcus. Flowers (4) recommended the use of tear trough implants for correction of the "tear trough" deformity.

These techniques are very useful, but it is preferred to manage the underlying pathology. One can raise the premalar fat pad with the superficial musculo-aponeurotic 
system (SMAS) which fills in the infraorbital sulcus, creates a beautiful cheekbone, improves the nasolabial fold and relocates the fat of the jowl to improve the facial silhouette. In addition, the transposed SMAS can reduce the herniated fat pad, adding to the rejuvenation of the eye and the face (Table 1). This technique may lessen the risks of an inferior blepharoplasty, such as enophthalmia, scleral show, ectropion, dry eye syndrome and the possibility of a retrobulbar hematoma.

\section{TABLE 1: Benefits of raising the premalar fat pad with the superficial musculo- aponeurotic system}

- Fills in the palpebromalar groove

- Recreates a youthful cheekbone

- Improves the nasolabial fold

- Improves jowls

- Reduces lower eyelid fat pads

- Improves enophthalmia

- Improves dynamic crow's feet

To obtain a youthful and natural look, it is absolutely imperative to improve the infraorbital sulcus. Enophthalmia can be prevented if fat pads are not removed; proper management involves use of the capsulopalpebral fascia (5-8) or the transposed SMAS.

Fogli $(9,10)$ described transposing the SMAS in a video presentation at an International Society of Aesthetic Plastic Surgery meeting in New York and in recent publications. He stated that by covering the vertical (or lateral) fibres of the orbital orbicularis oculi muscle, dynamic crow's feet were greatly improved.

Because the intraorbital fat resorbs with time, herniated fat pads should rarely, if ever, be removed if one wants to prevent or improve the enophthalmia of ageing. It is more physiological to reduce and maintain the reduction of the herniated fat pad by using the SMAS or the capsulopalpebral fascia (5-7). If the SMAS is used, it should be manipulated to relocate the premalar fat pad in order to improve the infraorbital sulcus.

\section{TECHNIQUE}

The subcutaneous dissection is done in a classical manner; the SMAS is incised horizontally over the zygomatic arch towards the tragus. The incision then continues downward to incise the platysma. The SMAS is undermined usually beyond the zygomaticus major muscle using a number 10 blade or straight Metzenbaum scissors. As described by Connell (personal communication) the SMAS is freed to a point that will allow upward and lateral movement of the buccal commissure and the tip of the nose as traction is applied. Instead of excising a wedge of the superior SMAS, it is raised intacted and attached to the temporal fascia. This raises the premalar fat pad to cover the zygomatic arch, restoring a high cheekbone and obliterating the infraorbital groove. It also covers the reduced herniated fat pad because it buttresses the orbicularis oculi muscle and improves dynamic crow's feet. Figures 1,2 and 3 provide examples of the results of the procedure. 

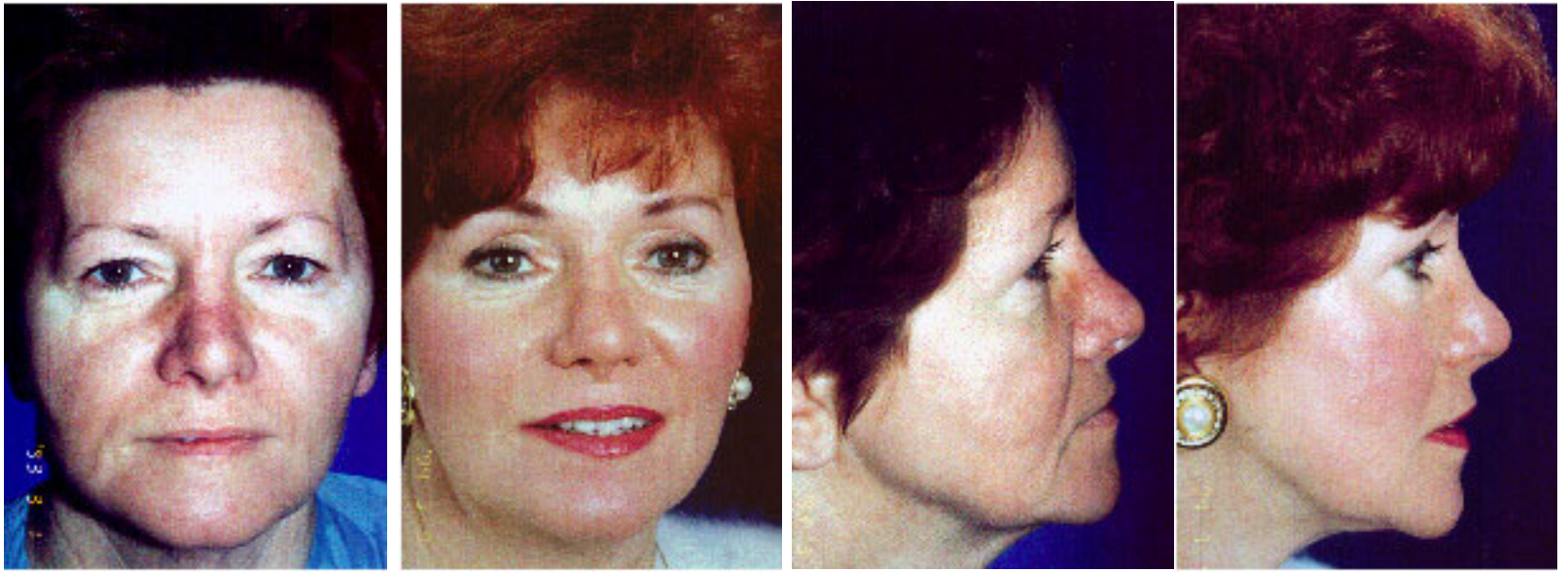

Figure 1) Frontal views of a patient showing the infrasulci and herniated fat pad (top left) corrected by raising the premalar fat pads using the superficial musculo-aponeurotic system to fill the infraorbital sulci and reduce the herniated fat pads (top right). Lateral views of the same patient (bottom left and right)
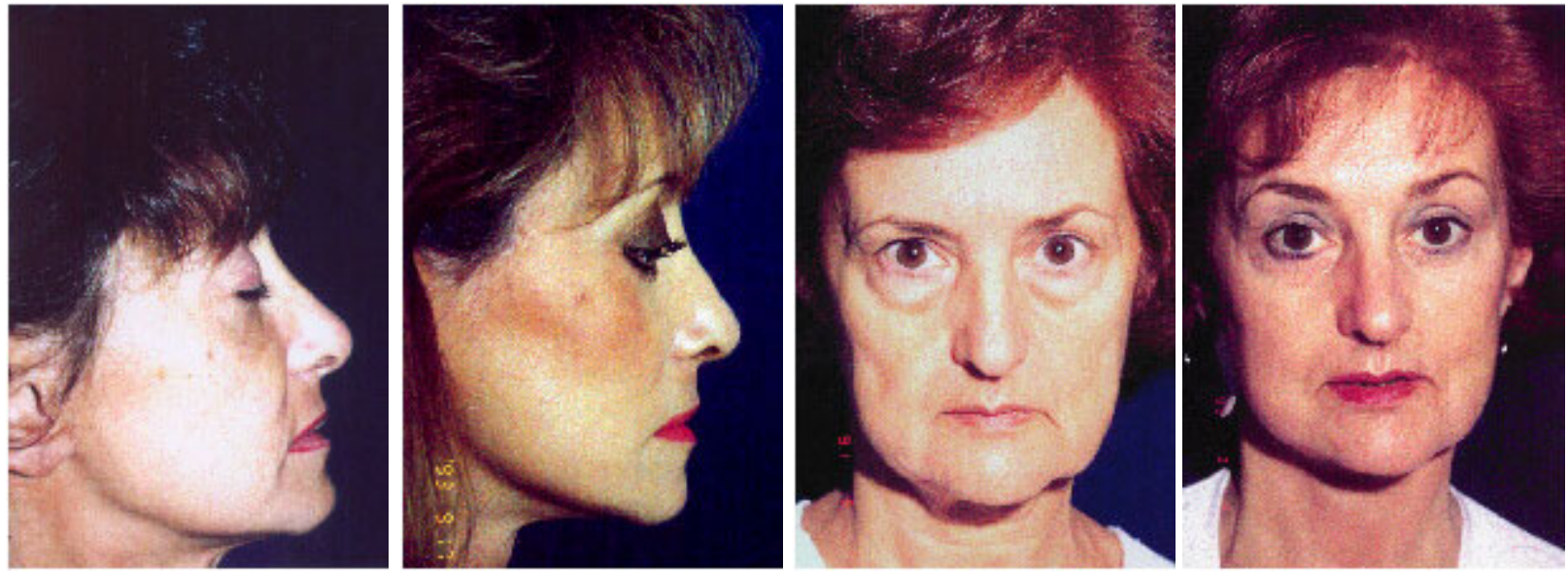

Figure 2) Lateral views of a patient showing an infraorbital sulcus and herniated fat pad (left) corrected by raising the premalar fat pad using the superficial musculo-aponeurotic system to fill the infraobrital sulcus and reduce the herniated fat pad (right).
Figure 3) Preoperative (left) and postoperative (right) pictures of a patient with palpebromlar grooves managed by raising the premalar fat pad using the superficial musculo-aponeurotic system 


\section{REFERENCES}

1. Charpy A, Nicholas A. Traité d'Anatomie Humaine. Paris: Masson, 1912.

2. Loeb R. Naso-jugal groove leveling with fat tissue. Clin Plast Surg 1993;20:393-400.

3. Hamra ST. The role of orbital fat preservation in facial aesthetic surgery: A new concept. Clin Plast Surg 1996;23:17-28.

4. Flowers R. Tear trough implants for correction of tear trough deformity. Clin Plast Surg 1993;20:403-15.

5. Camirand A. Canthopexy and transconjunctival blepharoplasty are preferable to lower blepharoplasty. Can J Plast Surg 1993/94;1:184-7.

6. Camirand A, Doucet J. Reinforcing the orbital septum of the eye through a transconjunctival approach. Oper Tech Plast Reconstr Surg 1994;1:160-71.

7. Camirand A, Doucet J. Surgical advances: a comprehensive approach to surgical rejuvenation of the eyes. Aesthetic Plast Surg 1996;20:15-22.

8. Camirand A, Doucet J, Harris J. A modern and physiological concept of eyelid rejuvenation. Can J Plast Surg (in press).

9. Fogli A. Muscle orbiculaire et patte d'oie: étude pathogénique et approche chirurgicale. Chirurgie Plastique Esthétique 1992;37:510-8.

10. Fogli A. Orbicularis muscleplasty and face lift: a better orbital contour. Plast Reconstr Surg 1995;96:1560-70. 